Koninklijke Vereniging voor Nederlandse Muziekgeschiedenis

Het orgel van de Nicolaïkerk te Utrecht

Author(s): J. C. M. van Riemsdijk

Source: Tijdschrift der Vereeniging voor Noord-Nederlands Muziekgeschiedenis, Deel 2, 3de

Stuk (1887), pp. 195-199

Published by: Koninklijke Vereniging voor Nederlandse Muziekgeschiedenis

Stable URL: http://www.jstor.org/stable/947969

Accessed: 20/06/2014 18:50

Your use of the JSTOR archive indicates your acceptance of the Terms \& Conditions of Use, available at

http://www.jstor.org/page/info/about/policies/terms.jsp

JSTOR is a not-for-profit service that helps scholars, researchers, and students discover, use, and build upon a wide range of content in a trusted digital archive. We use information technology and tools to increase productivity and facilitate new forms of scholarship. For more information about JSTOR, please contact support@jstor.org. 


\section{HET ORGEL VAN DE NICOLAÏKERK TE UTRECHT.}

Dit orgel, dat in de muziekgeschiedboeken en in de literatuur over het orgel nog altijd geciteerd wordt als een der oudste bestaande instrumenten. heeft zijn standplaats niet meer in Utrecht, maar prijkt, thans in een der groote zijzalen van het Rijksmuseum te Amsterdam. Voor kerkgebruik was het reeds sedert jaren ongeschikt. Toen men in Utrecht eindelijk besloot het door een nieuw te vervangen, heeft onze Vereeniging zich het lot van het oude instrument aangetrokken en heeft zij bewerkt, dat het eene plaats kreeg onder de monumenten van onze vaderlandsche kunst, die in het Rijksmuseum worden bijeengebracht.

Eene zeer uitvoerige en juiste beschrijving van het oude orgel van de Nicolaïkerk vindt men in het derde Jaarboek onzer Vereeniging blz. 92-100. De deskundige schrijver, de heer J. F. Witte, de bekënde Utrechtsche orgelbouwer, heeft daarin de technische inrichting van het instrument beschreven en de bistorische waarde daarvan uitvoerig toegelicht. Die leschrijving is zoo volledig, dat zelfs een nieuw onder\%oek van de rekeningen der $15^{\text {de }}$ en $16^{\text {de }}$ eeuw van de Nicolaïkerk ons niet in staat stelt daaraan veel belangrijks toe te voegen.

Evenmin is er bij het uit elkander nemen van het orgel, (hetgeen op zeer zorgvuldige wijze is geschied door de firma H. Maarschalkerweerd te Utrecht, aan wie het opstellen van het orgel in het Rijksmuseum was opgedragen), iets gevonden of ontdekt. dat tot nieuwe gezichtspunten aanleiding geeft. 
Nieuwe gegevens aanguande den ouderdom van het orgel zijn niet aan het licht gekomen.

Zijne historische vermaardheid ontleent het instrument vooral aan eene mededeeling van Lootens, te vinden in de »korte schets van de allereerste uitvinding en verdere voortgang in het vervaardigen der orgelen tot op dezen tijd van Joachim Hess." Volgens dit citaat zou een zekere Albertus van Os omstreeks het einde der 17de eeuw bij zijne werkzaamheden aan het orgel in de Nicolaïkerk, daarin het jaartal 1120 gevonden hebben. Men heeft bij het afbreken nauwkeurig onderzocht of ergens dit jaartal te ontdekken was, maar geen spoor heeft men er van kunnen vinden.

Voor de geschiedenis der orgelbouwkunst is het orgel daarom zoo belangrijk, omdat men daarin vereenigd vindt drie verschillende opeenvolgende stelsels, namelijk het blokwerk, de springladen en de sleepladen. De heer Witte beschrijft die stelsels aldus:

\Hoewel van de alleroudste orgels weinig of geen goede beschrij》vingen en af beeldingen meer bestaan, kan toch veilig worden aan"genomen, dat deze slechts een zeer beperkt aantal pijpen bevatten, )en dat op iedere klaviertoets steeds slechts één enkele pijp sprak. ) $0 \mathrm{~m}$ het geluid meerdere kracht en glans te geven, kwam men toen »op het denkbeeld, om in plaats dier enkele pijp telkens een choor ) van meerdere pijpen te zamen te laten spreken, welke zuiver unisono 》of in octaven stemden en dus een harmonisch geheel vormden. Dit )is hetgeen men blokwerk heet. Al spoedig bleek evenwel de 》wenschelijkheid om deze verschillende reeksen pijpen of zoogenaamde )registers ook afzonderlijk te kunnen gebruiken, en op die wijze naar ) verkiezing het geluid sterker of zwakker te kunnen maken. Dit „nu werd eindelijk bereikt door de uitvinding der springladen en )later nog verbeterd door de invoering der sleepladen, bij welke »beide inrichtingen de bespeler door eenvoudige verschuiving eener »knop, den windtoevoer van elk register kan afsluiten of openstellen »en dus naar welgevallen iedere stem afzonderlijk of in vereeniging »met andere kan gebruiken."

Uit het aanwezig zijn van het blokwerk in het orgel der Nicolaïkerk mag men den hoogen ouderdom van dat orgel afleiden: want, zooals de heer Witte terecht zegt, het is zeer te betwijfelen 
Doorsnede en details van het oude Orgel uit de $\mathrm{Ni}$

opogerneten enc geteekend door

\section{MAARSCHALKERW \\ Urgehmorkor te Ultirchlit, $A^{0} 188$}
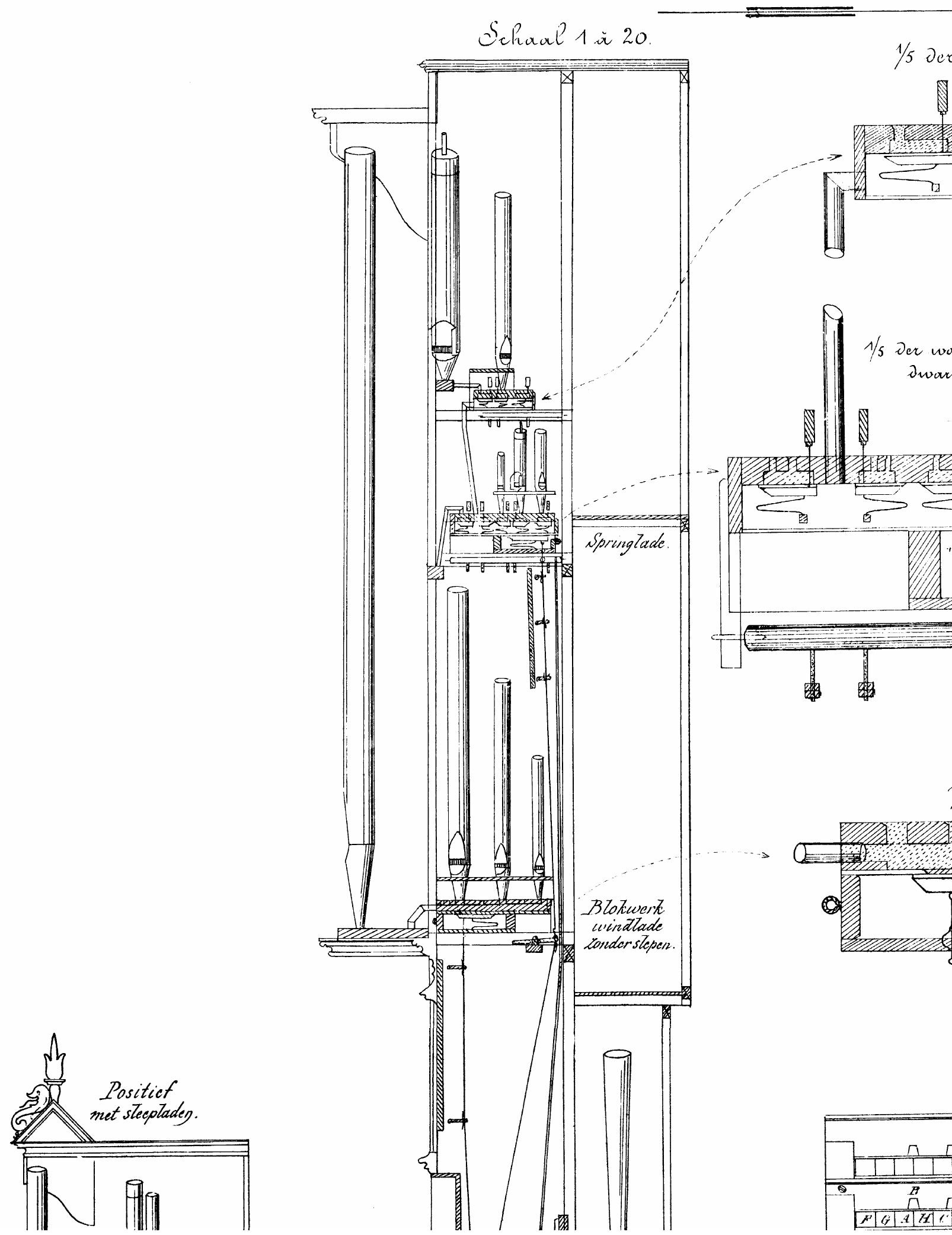

This content downloaded from 91.229.248.182 on Fri, 20 Jun 2014 18:50:54 PM All use subject to JSTOR Terms and Conditions 
op ogerneten en oुeteekend

door

\section{AARSCHALKERWEERD}

gelunorkar te Ulirecht, $\mathrm{A}^{0} 1886$.

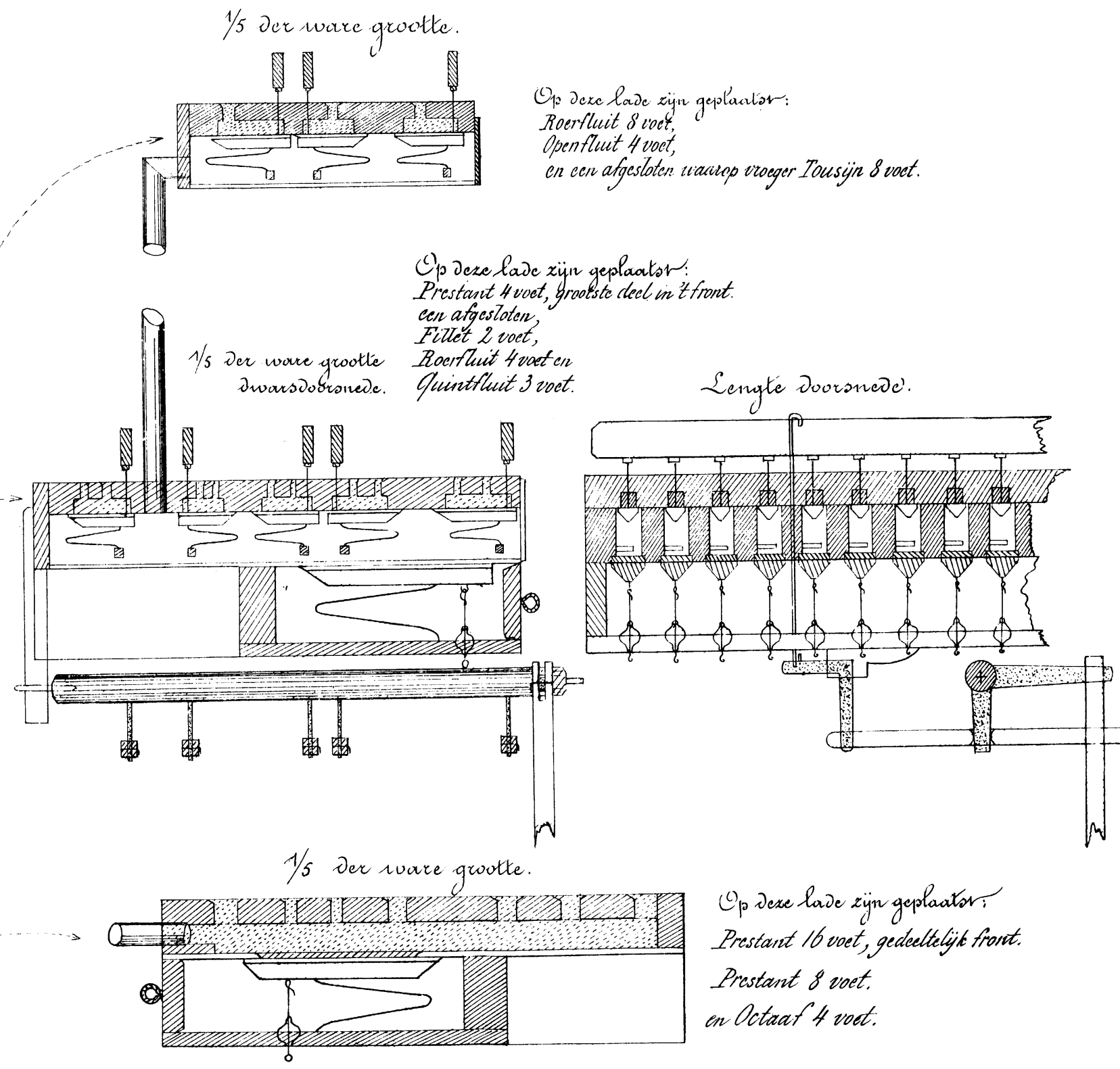

1/s Jer waveren grootte.

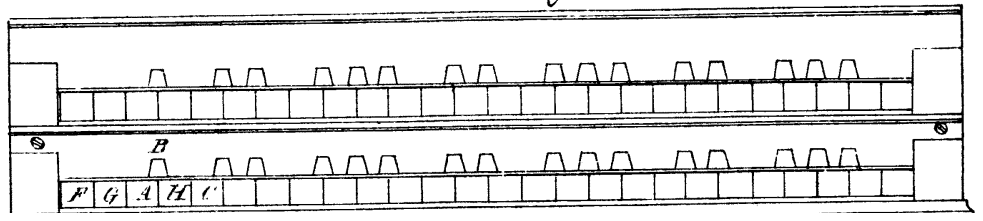

This content downloaded from 91.229.248.182 on Fri, 20 Jun 2014 18:50:54 PM All use subject to JSTOR Terms and Conditions 


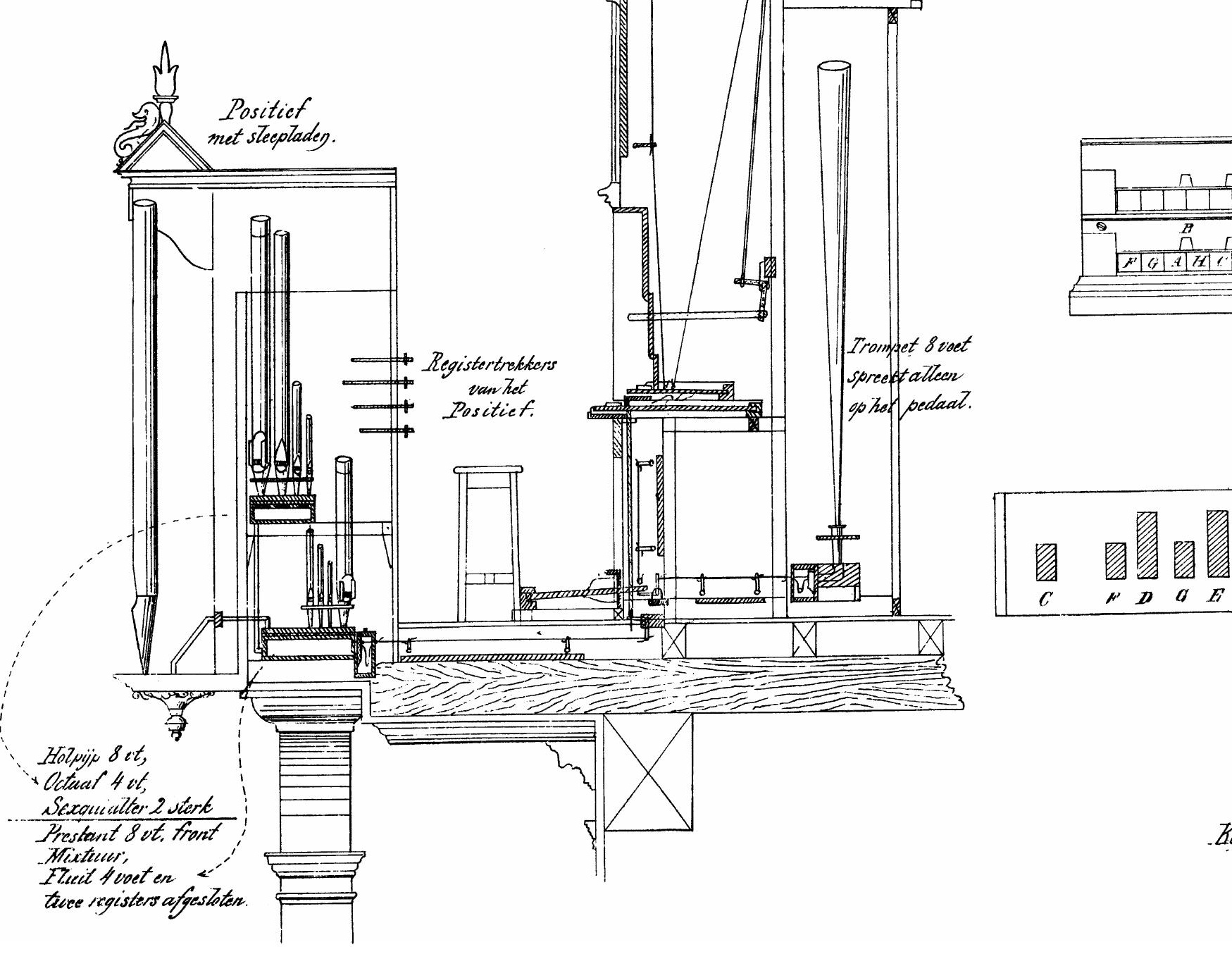


$1 / \mathrm{s}$ Der wave arootte Fitlet 2 voet,

awarsoodronede. Guintfluit 3 voet.

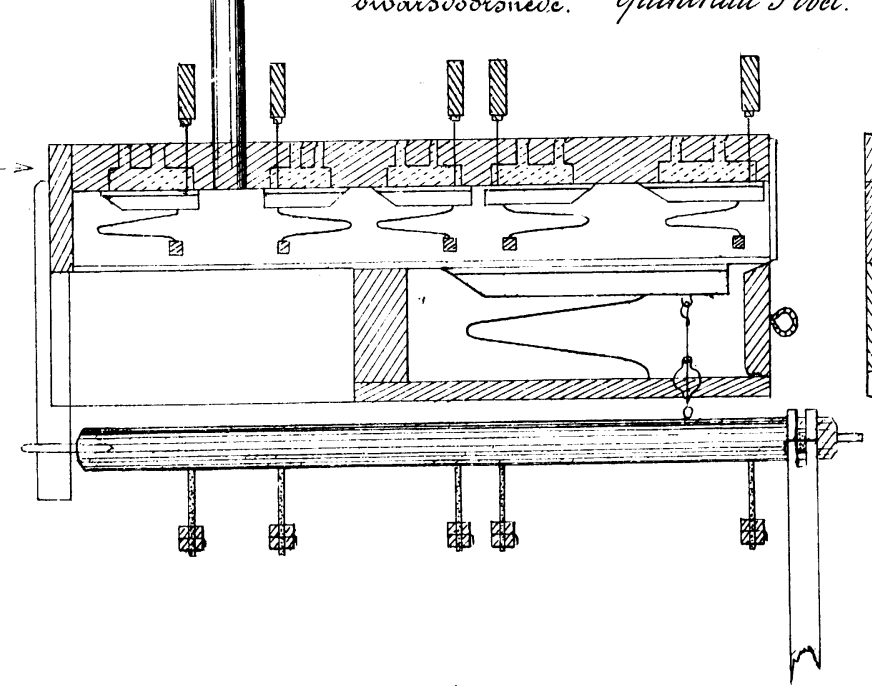

Senuté Dooranede'.

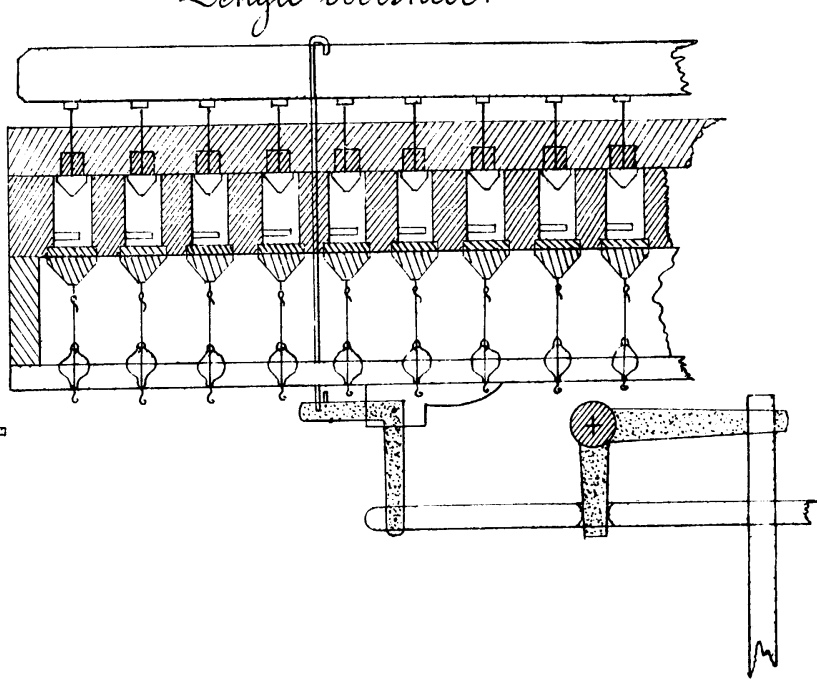

$1 / 5$ Der nuare grootte.

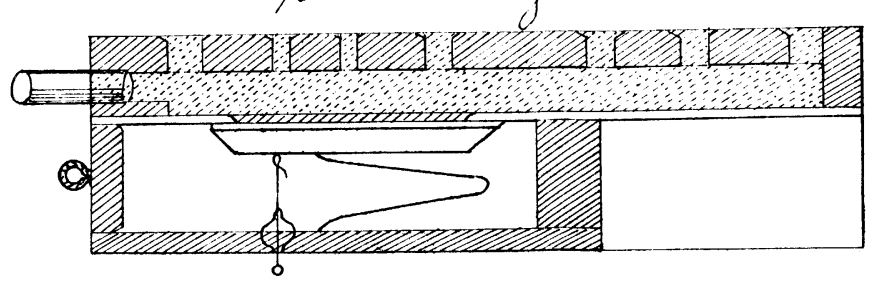

(c) p Dexe lave zün geplaator: Prestant 16 voet, gedeeltelyk front. Prestant 8 voet. en Octaaf 4 voot.

T/S Javieren
der ware groatte.

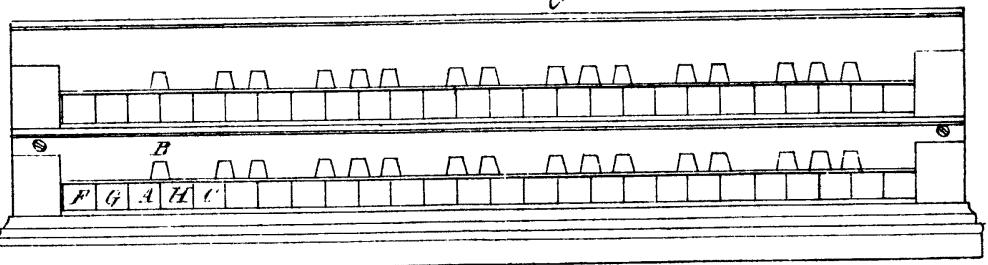

mplet 8 voet cetat atlear et pedaal.

Gedaal $1 / 5$ Der ware yrootte.

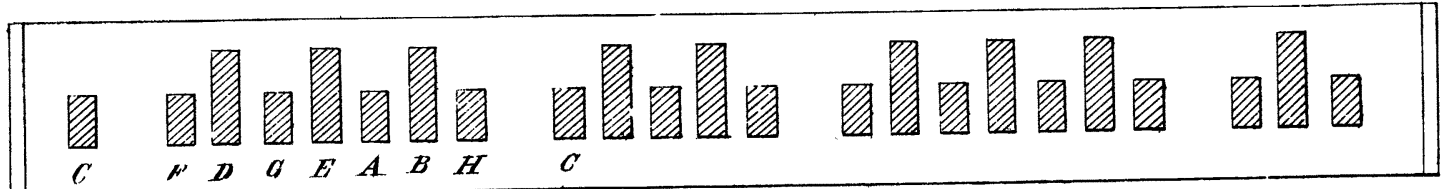

- Vier YLindafoluitingey, als:

1. Afstuiting voor het Pasiticf,

2. Jdenv" "Blokwerk,

3. Jdann " de Springlader

4. Jdem " "Irompet 8 voet.

Koppeling der beide Klavieren door vowchusiving oun het Bovernklavier 
dat men een blokwerk zou hebben aangebracht, nadat de springladen, die in de $15^{\text {do }}$ eeuw werden uitgevonden, in algemeen gebruik waren gekomen. Orgels met blokwerken moeten minstens vier eeuwen oud zijn.

Of nu het blokwerk van het orgel in de Nicolaikerk afkomstig is van een orgel van vroegeren datum, is natuurlijk niet na te gaan. Zeker is het evenwel dat er in de Nicolaïkerk een orgel bestond in het begin der 15de eeuw. De rekeningen der Nicolaïkerk van het jaar 1429 maken melding van een sschoolmeyster van orghelen"; in 1436 wordt Aelbert Goyertszn. als de organist genoemd: in 1441 treffen wij den naam aan van )Goyert Goyertszn. van den Gheer" die nog in 1459 als organist voorkomt. De rekeningen van 1472 spreken van Meyster Gherūt. In 1471 werd het orgel wat versteli en in 1474 wordt het tweemaal )verset", misschien om plaats te maken voor het nieuwe orgel, dat in 1477 werd anbesteed. In dat laatste jaar vinden wij dan ook vermoedelijk de eerste sporen van ons orgel.

"Item geg. te oncost doe die orgell bestaet wert 17 crst. Item geg. "Peter die orgellmaker, op de nywe orgell 20 Rijksgulden." In 1/477 werd dus aan Peter bij vooruitbetaling eene som gelds ter hand gesteld. In 1478 wordt een bedrag uitgetrokken voor )Cornelis van „Rewick" van die orgel te stofferen ende te schilderen", terwijl in 1481 aan Meyster Peter die orgelmaker wordt betaald »89 Rijnsgulden facit 238 Arnoldusgulden 10 cromstert", waruit men kan opmaken, dat het orgel in dat jaar voltooid en afgeleverd werd.

Twijfelachtig is het, of toen reeds een positief aan het orgel werd aangebracht; in elk geval vertoont de bouwstijl van de kast van het thans bestaande positief een groot verschil met dien van de kast van het hoofdmanuaal. Waarschijnlijk werd eerst het positief aangebracht in het jaar 1580 door Mr. Bernt uwt ten Eng, orgelmaker, aan wien volgens de rekening manbesteyt werd dat hij een groot orgel ) soude maecken ende daertoe employeren die pypen van de twee )cleyne orgelkens", die dus vermoedelijk nog in de kerk aanwerig waren. Het bestaan van die kleine orgels wordt bevestigd door het feit, dat de in de rekeningen van 1555, 1561 en andere jaren voorkomende beschrijvingen van orgelreparatiën gedurig spreken van het "groote orgaen." 
$\mathrm{Na} 1481$ komen in de rekeningen voor de namen der volgende organisten :

1484 Meyster Meerten, 1493--1499 Henric Gerytsz,, 1503 Henric Nobel, 1507 Henric Geritz., 1514 Jannys, 1516 Mr. Jan, 1547 Rietvelt, 1563 H. Bruno, 1561, 1564 Jan Kuyter, 1571 en 1572 Peter Adryaentsz., 1575 Peter Augustynszn., 1576 Mr. Augustyn, Peter Aertszn., 1580, 1585, 1599 Peter Augustynsz uyten Bongaert.

Als orgelmakers worden genoemd na Meester Peter, die in 1481 het orgel afleverde:

1503 Mr. Gheret, 1533 Mr. Cornelis Gerritszn., 1563 Jan Cater, 1573, 1575, 1579, 1580 Mr. Bernt wten Eng.

Een volledige lijst van de organisten der Nicolaïkerk zal kunnen gegeven worden, zoodra het onderzoek der rekeningen van de $17^{\mathrm{do}}$ en $18^{\mathrm{de}}$ eeuw, door den heer Jhr. Mr* F. A: L. Ridder van Rappard ons welwillend toegezegd, zal zijn afgeloopen. Vermoedelijk zal dan daarop ook voorkomen "Carel Valbeeck" die zijn naam op het deksel van het klavier heeft ingesneden op de volgende wijze: »Carel Valbeeck anno 166012 Marti Aetatis 16." Deze »Valbeeck" was een veelbelovende Utrechtsche jongen, zoon van een schoenmaker, die door de Vroedschap in 1657, dus reeds op dertienjarigen leeftijd, »met vijftien gulden vereert werd" tot een cleedt om hem te animeren tot continuatie ende vorderinge in de musycke; in 1658 werd de tromper »Justus Servaes de Clermont" door de Vroedschap aangewezen om zich te belasten met de verdere opleiding van dien talentvollen jongeling, die later tot stadstromper en tot organist van den Dom werd benoemd. ${ }^{1}$ )

Kon het meer dan 400 jaren oude orgel spreken, hoe zou het kunnen gewagen van menige belangrijke bijzonderheid aangaande den dienst in de Nicoläkerk in vervlogen eeuwen! Hoe zou het kunnen getuigen van de meerdere of mindere bekwaamheid van die breede schare van organisten, die het hebben bespeeld! Thans zal geen hand meer tonen daaraan kunnen ontlokken; want het staat in het Rijksmuseum ontdaan van zijne windinrichtingen; overigens is het

1) Zie J. C, M. van Riemsdijk: het stads-muziekcollegie te Utrecht blz. 39 en 40 
opgesteld in denzelfden toestand, zooals het zich in de kerk vertoonde. Men kan dus daar ter plaatse met behulp van de teekening van de doorsnede en details, die door den heer Maarschalkerweerd vervaardigd en hiernevens afgedrukt is, zijne primitive uit- en inwendige inrichting bestudeeren. Zijn dienst in de kerk heeft het instrument eerst geweigerd, toen in het jaar 1885 de noodige gelden voor een nieuw orgel waren bijeenverzameld. In een Zondagochtendbeurt in de maand Mei 1885 kon het nog den voorzang begeleiden, maar het was den organist nlet meer mogelijk om voorttegaan; zijn gewoon krijschend en kreunend geluid kon het oude instrument zelfs niet meer voortbrengen. Zijn bede om »rust", geslaakt bij monde van onzen Nicolaas Beets en geschreven onder de door den heer Mengelberg vervaardigde fraaije teekening ${ }^{1}$ ) van de gothische kast van het hoofdmanuaal, welke den bezoekers van de bazar, gehouden te Utrecht in April 1885 voor het nieuwe orgel, werd aangeboden, is thans verhoord:

„Vier eeuwen paarde ik roeds mijn klanken aan uw psalmen.

n'k Ben veel gebreks, maar van goen onwil mij bowust.

„Thans is mijn keol verroest, en kreunt in plaats van galmen;

Mijn adem weigert .. Ei, vervang me en gun mij rust!

Utrecht, October 1886.

J. C. M. van RiemsdiJK.

1) Exemplaren van doze teckening worden tegelijkertijd mot de bezurging dezer aflevering aan de Leden onzer Verecniging toegezunden 